\title{
Deciphering of Space Images of the Inder Salt-Dome Upland in ENVI 4.7 Program
}

\author{
K. M. Akhmedenovi ${ }^{*}$, A. G. Koshym², R. Z. Zhumabekova ${ }^{3}$ \\ ${ }^{1}$ Scientific Research Institute of Biotechnology and Nature Management at the West Kazakhstan Agrarian \\ Technical University Named of Zhangir Khan (WKATU), Uralsk, Republic of Kazakhstan \\ ${ }^{2}$ Department of Cartography and Geoinformatics, Al-Farabi Kazakh National University, Almaty, \\ Republic of Kazakhstan \\ ${ }^{3}$ Institute of Space Research, Almaty, Republic of Kazakhstan \\ Email: ${ }^{*}$ Kazhmurat78@mail.ru
}

Received 24 December 2013; revised 22 January 2014; accepted 21 February 2014

Copyright (C) 2014 by authors and Scientific Research Publishing Inc.

This work is licensed under the Creative Commons Attribution International License (CC BY). http://creativecommons.org/licenses/by/4.0/

(c) () Open Access

\section{Abstract}

Space images play an important role in the Earth study as they bring the main information received from the Space Flyer Units (SFU) to help researchers. Space images' deciphering gives the opportunity to study the territory and to plot different maps. On the basis of the space image obtained from Landsat 5TM (30 m resolution, 01.09.2012 year), we managed to get a picture of the modern relief of the northern part of Inder lake. When comparing the space image with topographic maps of 1985, we succeeded to identify the dynamics of landforms change on the studied area, what has been shown on the drawn map of the relief of the Inder salt dome uplift. 14 classes, corresponding to a particular type of terrain or to a landscape complex, have been distinguished on the studied area. Inder salt dome uplift is a paradynamic conjugation, consisting of highly karsted Inder Mountains corresponding to large diapir uplift, and of the Inder Lake having a large ellipsoidal shape. Geomorphologically, the investigated territory is located on the left bank of Zhaiyk River, and presents a salt dome uplift in the form of a plateau-like hill raised above the surrounding surface from 12 to $40 \mathrm{~m}$. The maximum height reaches $42.5 \mathrm{~m}$ (g. Suatbaytau). The crest of the Inder salt dome is composed of Low Permian sediments (rock salt with anhydrite, potassiummagnesium salts), and has an area of about $210 \mathrm{~km}^{2}$. Inder lake's basin is represented by a tectonic depression, which is the local basis of erosion and is a drainage place of the Inder uplift karstic water. The lake area is $150 \mathrm{~km}^{2}$. Depending on the climatic conditions, the water level can vary.

\section{Keywords}

Space Image; Inder Salt-Dome Uplift; Karst Relief; Exogenous Processes; Karst Processes; Relief Shapes; Basis of Erosion; Automated Deciphering; Vector Layer; Objects Classification;

\footnotetext{
"Corresponding author.
} 


\section{Object Classes; Landscapes Complex; Mapping}

\section{Introduction}

Scientific interest to the use of remote sensing methods in studying of the Earth and the planet's natural resources has reached a higher level through the multizone photography modes [1] [2], which allowed getting information that could be used both for the improvement of universal maps' contents and for specific maps' drawing [3], [4]. Development of new methods of automatic image processing, by means of GIS-programs, contributed to the success of multizone photography [1].

Analyzing materials of the space surveys, it should be noted that these materials should be supplemented with the number of various ground and air methods for distance studying of underlying surface using cartographic material, and studying the characteristics of brightness of underlying surface will allow using them in thematic deciphering and in maps' drawing of the studied area [5] [6].

Relief deciphering is focused on the achievement of the "geographic likelyhood" on maps. It has the maximum indication value as it could be very easily read on the images. There is a certain connection between the morphologic and morphometric peculiarities of modern relief, endogenous and exogenous processes, geologic structures, surface and subsurface waters, flora and subsoil [7].

\section{Materials and Methods}

\subsection{Research Object}

The Inder lake area, which is characterized by peculiar karstic shapes, was chosen as the object of study. The Inder lake is located on the Atyrau region territory in West Kazakhstan. The region is the largest area of the karst shapes' development in Kazakhstan. The Inder lake area has been studied on summer, 2013. For that purpose, a morphogenetic method of study has been chosen. Various karstic forms, lithological composition, dynamics of development and their order on the topographic maps have been studied there. The collected information was, then, processed and analyzed. As the result, the morphographic and morphometric parameters of karstic forms of relief have been identified.

\subsection{Geomorphologic Characteristics of the Research Object}

According to geomorphology, the Inder lake area is located on the left bank of Zhaiyk River and represents saltdome uplift in the form of a plateau-like upland 12 - $40 \mathrm{~m}$. above the surrounding surface. The maximum height reaches $42.5 \mathrm{~m}$ of Suatbaitau Mountain. The crest of Inder salt-dome is composed of Low Permian sediments (rock salt with anhydrite, potassium-magnesium salt). Its area is about $210 \mathrm{~km}^{2}$ (measures taken from space image). The Inder lake basin is represented by tectonic depression, which is a local basis of erosion and drainage area of Inder uplift karst waters. The lake area is $150 \mathrm{~km}^{2}$ (measures taken from space image).

The northern coast of the lake is presented by a cleve; its height in places is 15 - $20 \mathrm{~m}$ and more; the south coast is flat.

The lake water is bitter-salty, local people even compare it with the Dead Sea, which is in the Middle East, as one have to be either in horizontal or in vertical position only. Northern coast is fed from the source, which is located in the bottom of slope that can be seen on space image (by its colour).

There is the Inder salt-dome in northern part of the lake, composed of gypsum rocks, with the capacity of 60 m. Most part of upland presents cuesta-shaped ridges, which height varies mostly from 20 to 40 m. The karst processes are actively developed on the surface of Inder salt-dome. Karst forms' density comes to 200 - 300 units per $1 \mathrm{~km}^{2}$ [8] (Figure 1).

\subsection{Selection the Space Image of the Investigated Territory}

We ordered the $K A$ Landsat space image on the glovis.usgs.go site, which was created especially for naturalresource monitoring of different territories.

The peculiarity of the Landsat 5TM image is its electro-optical TM camera and an upgraded scanner MS 


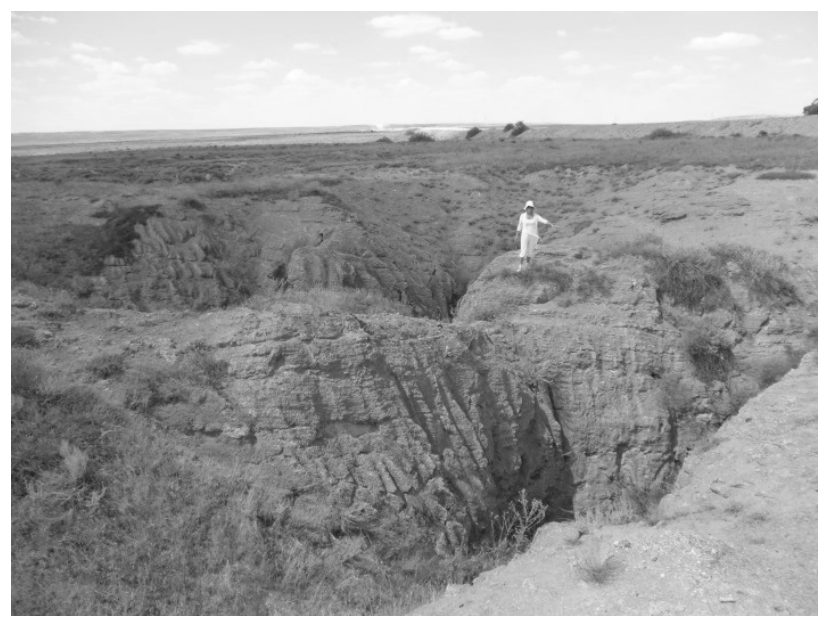

Figure 1. Karst evolution area.

(multispectral scanner). TM camera allows to form an image at seven places of the electromagnetic spectrum (with $30 \mathrm{~m}$ of spatial resolution), in the visible and infrared range with a swath width of 185 kilometers [8].

Large scale images, made in different periods, should be used for studies. They should cover all the studied territory, be of one type. The most high-quality images (without cloud cover), intended for mapping of coastal water surfaces are selected. Such was an image taken at the end of summer period of 2012, with the spatial resolution of $30 \mathrm{~m}$. We managed to see a picture of modern Inder Lake's relief on the obtained space image (Figure 2). The correction and geographical junction/bridging was done by means of ArcGIS 9.3. program

\subsection{Binding of the Space Image in the ArcGIS/ArcMap Program}

As it is known, the geometry of the obtained images in most cases is accompanied by distortions. Consequently, it is difficult to perform accurate measurements. For the image geometry's restoration a photogrammetric processing of an image is carried out, during which the one-to-one correspondence between the points on the image and the same points on the earth's surface is detected. Also the geometric distortions of an image are eliminated [9].

The gridding in the ArcGIS/ArcMap software package is performed in several steps, the sequence of which depends on the type of a gridded material. We performed the cross line screen bridging in ArcGIS using tools from Spatial Reference (Georeferencing) panel. For this It was enough to know the coordinates of several points on the cross line screen or to have the vector data, which can be then compared with data on the cross line screen. We took the coordinates of Inder lake ( $48^{\circ} 33^{\prime}$ north latitude, $51^{\circ} 44^{\prime}$ south latitude), of Bodene village $\left(48^{\circ} 23^{\prime}\right.$ north latitude $51^{\circ} 38^{\prime}$ south latitude), and of the mine \#103 (48 $32^{\prime}$ north latitude $51^{\circ} 57^{\prime}$ south latitude) from topographic map (100,000 scale). After bridging the space images we marked out the borders Inder salt dome uplift in the northern part of the lake, i.e. the development area of karst relief (Figure 3).

\subsection{Space Image Processing in the ENVI 4.7 Program}

During the space image processing the signs (markers) of spectral brightness are used. That is why in the course of automated deciphering, the problem of determining the quantitative connections between the spectral brightness and the objects characteristics is solved. Distribution of pixels by classes happens in the spectral space.

Automated processing, used by us, is based on the fact that the studied object is characterized by a set of quantitative characteristics of its image, that form an image or signature. The image is automatically partitioned into elements, where for each of them the numerical values of signs/characteristics are determined, forming a multidimensional vector. The task of classification is to divide the signs/characteristics space into local regions corresponding to one class of objects. Also the program performs a reliable classification under the unique correspondence of signs/characteristics to the object. To increase the reliability, the textural signs are used in addition to the spectral ones. The shape and location of objects and information about the surrounding objects 


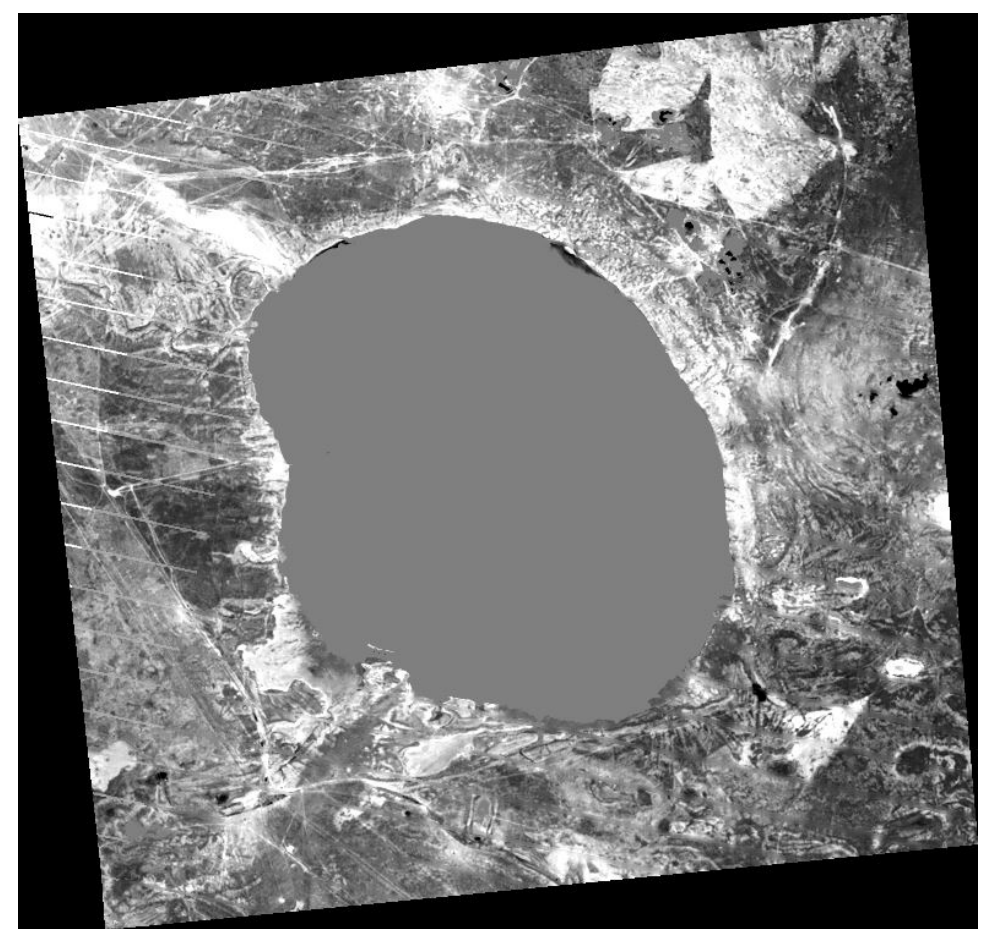

Figure 2. Space image of Inder Lake. The lake area is $150 \mathrm{~km}^{2}$.

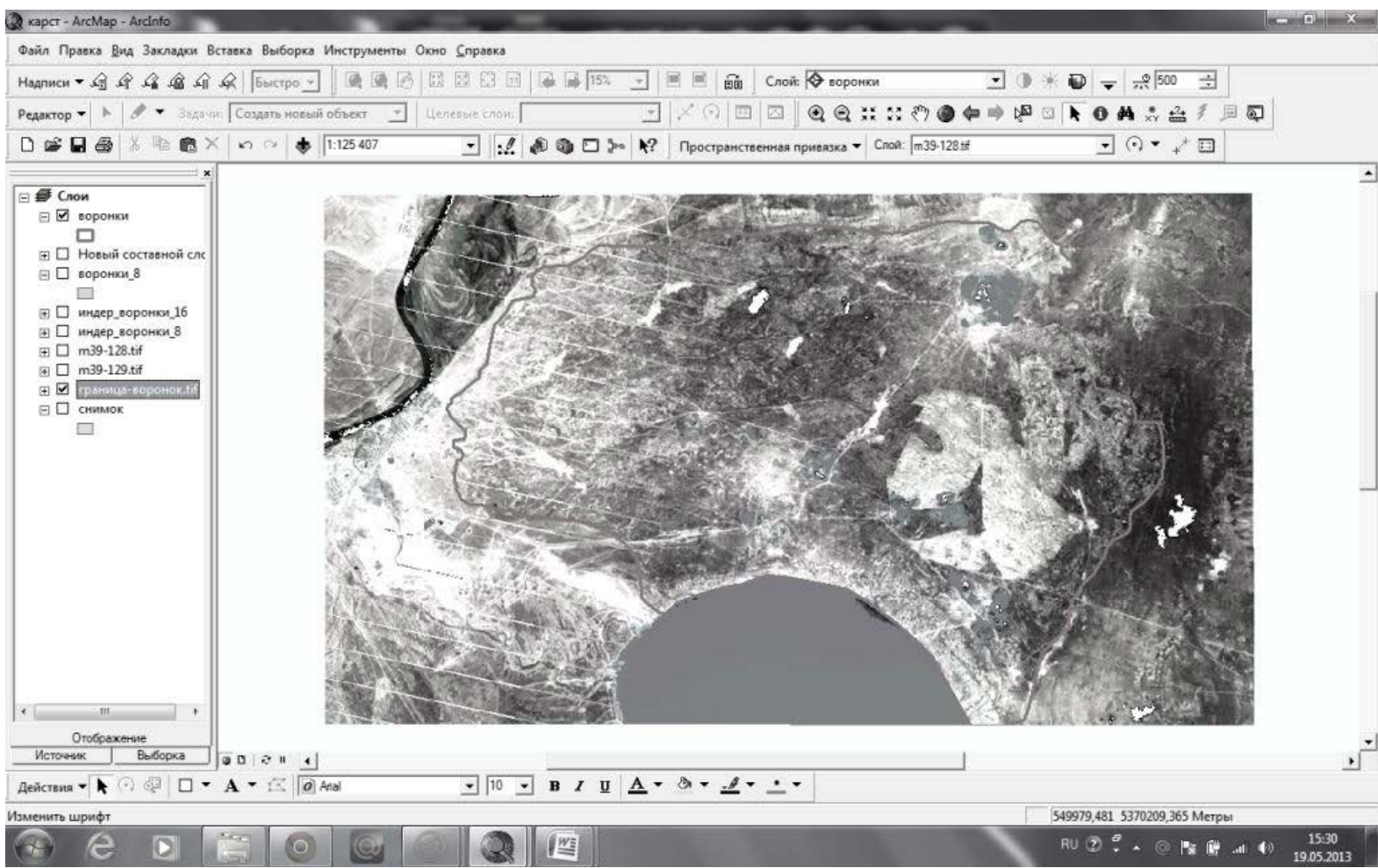

Figure 3. Junction/bridging of space image in and Inder salt-dome upland boundary detection.

are recorded. These signs increase the reliability of classification [9].

Space image processing is performed by classification method in the ENVI 4.7 program, where 255 akin colours are automatically highlighted. The task of the classification was to break the group of objects on the 
number of classes (in this case 14 classes), the number of iterations and convergence threshold. Then each class is assigned a color (Figure 4).

After dividing into 14 classes, each class in ROI format shall be transferred to vector layer for their use in GIS and shall be downloaded in another window (white contours, (Figure 4). The vector file in ENVI format (evf*) shall be resaved in the shape (shp).

\subsection{Objects Deciphering}

Further, the work shall be continued in ArcGIS program, where the recognition of objects and grouping of colors shall be carried out as per the attribute table. Also their combination or separation to classes shall be carried out as per the certain features (Figure 5).

Then, on a topographic base (Figure 6), we shall find the appropriate objects and classify them by comparing the objects, and using colors configuration of space image through three channels: 7, 4, 2 (Figure 7).

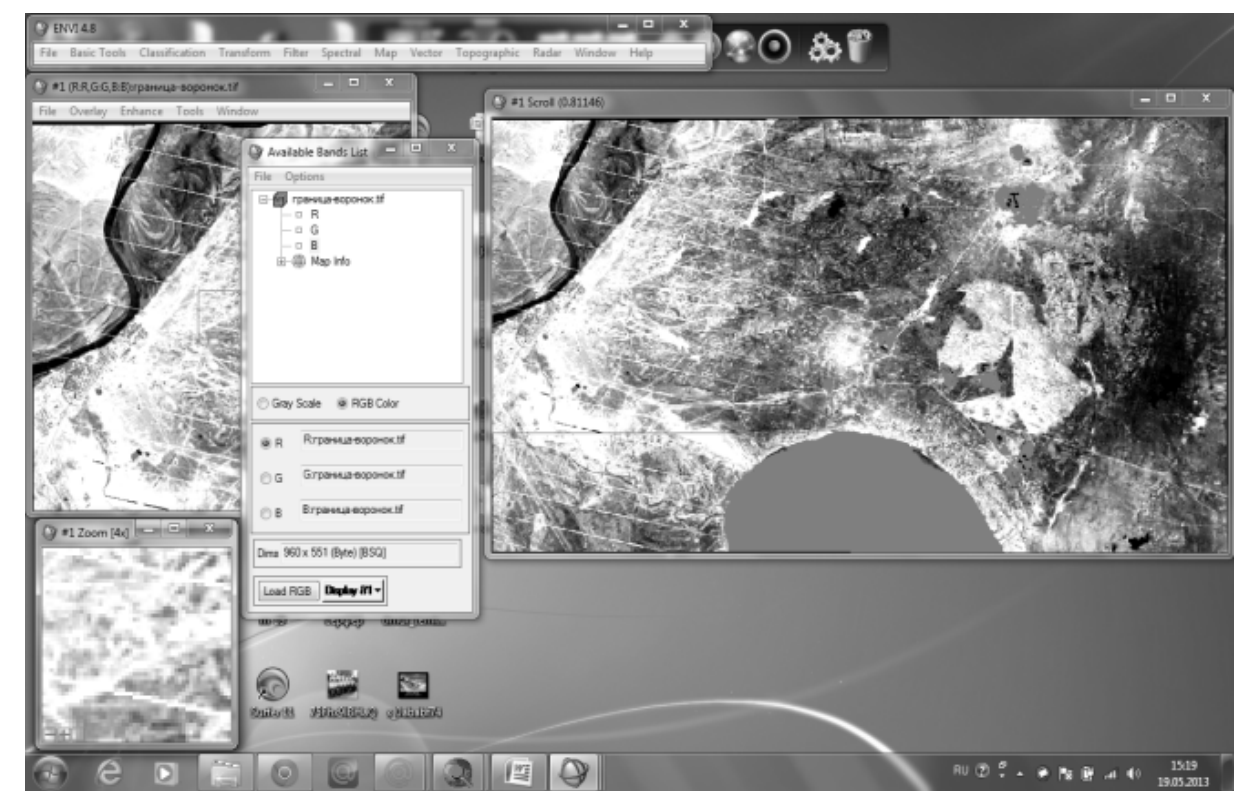

Figure 4. Space image processing in ENVI 4.7 program.

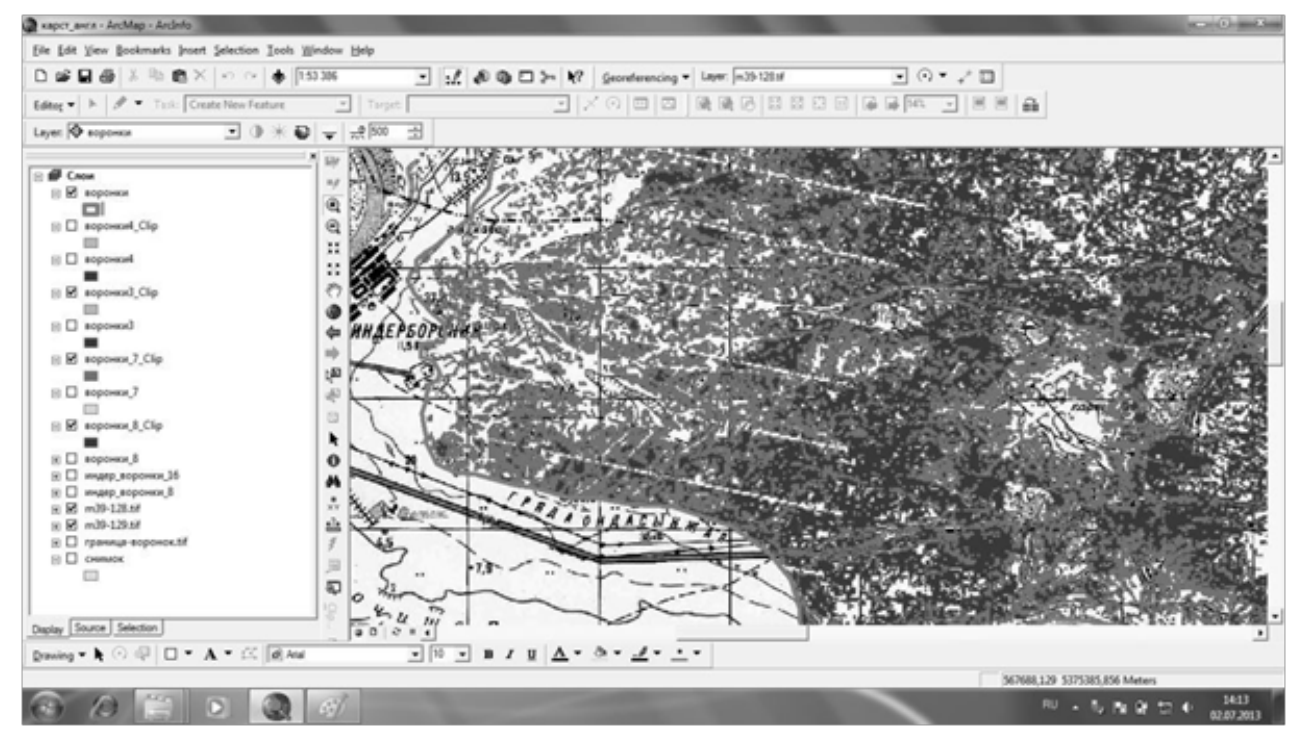

Figure 5. Selection of limestone sink types (by green color). 


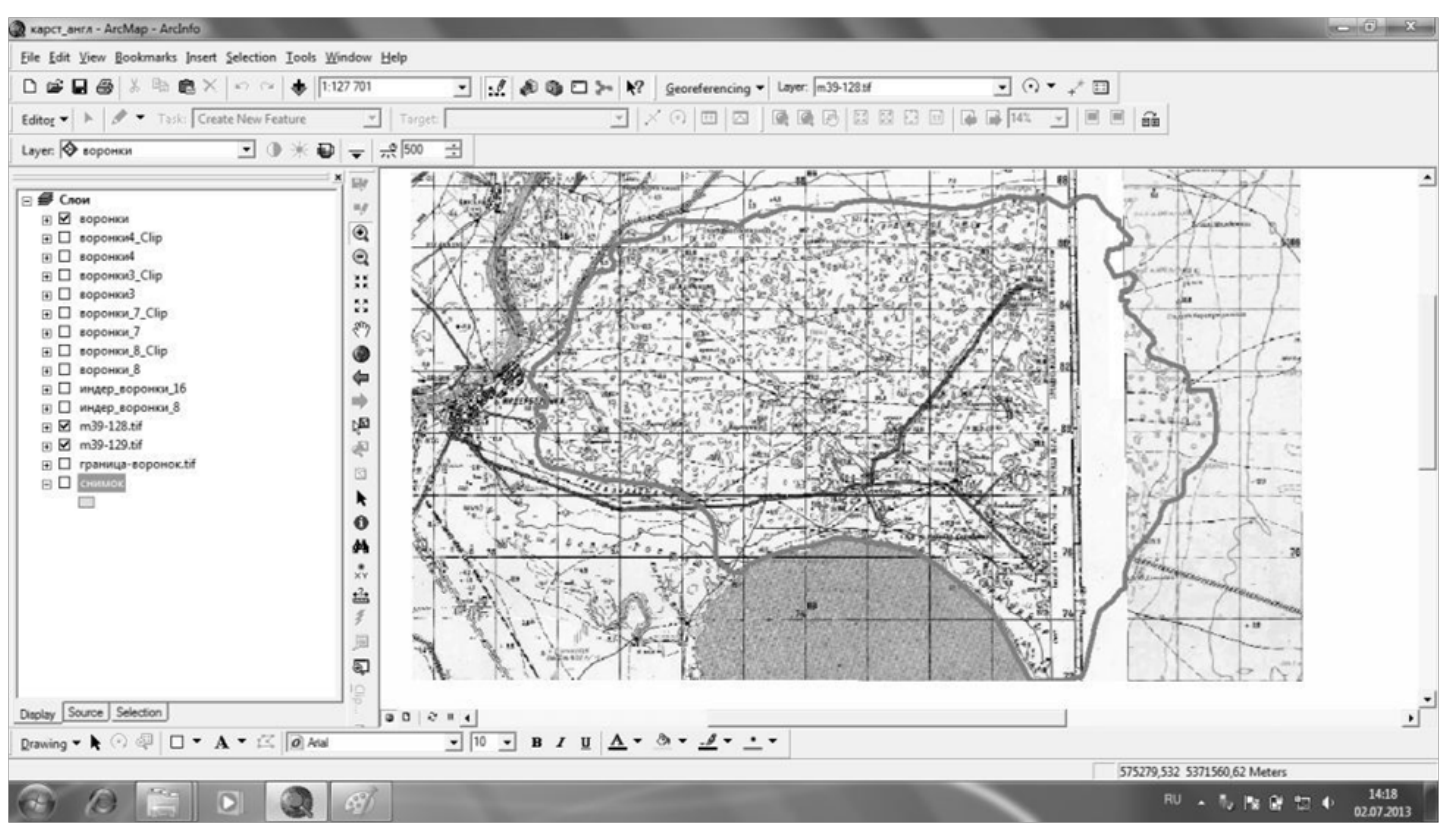

Figure 6. Karst sinkholes evolution area on the topographic map (1:100,000).

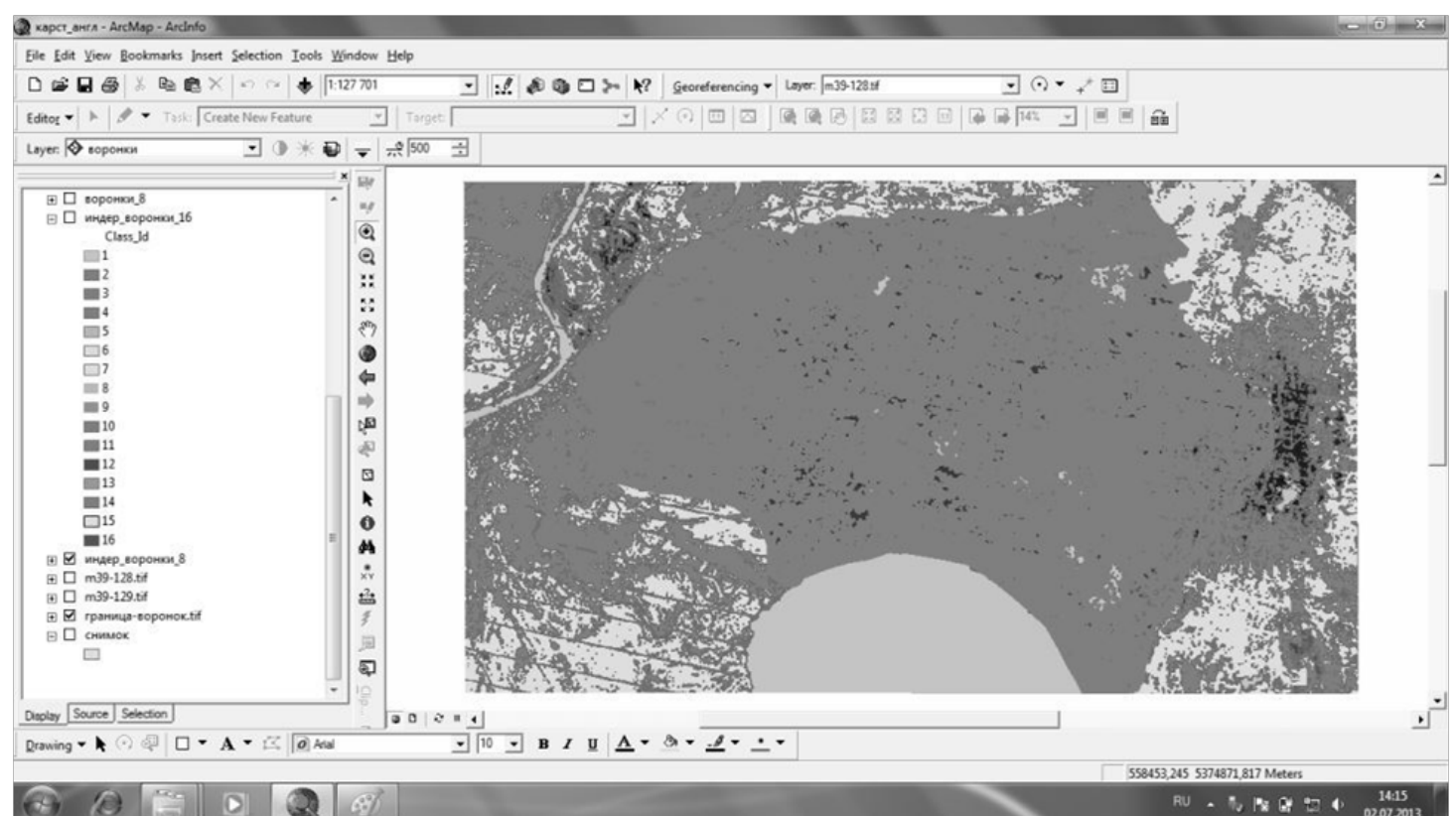

Figure 7. The process of isolating individual classes of objects.

\section{Results and Discussion}

\subsection{Objects Classification}

Thus, 14 classes, corresponding to a particular morphogenetic relief type or landscape complex, have been selected on the studied territory:

Class 1 -water objects;

Class 2-large karst sinkholes;

Class 3-average-size karst sinkholes;

Class 4-small karst sinkholes; 
Class 5-gypsum hills (dumps);

Class 6-quarries;

Class 7 -areas with thinned desert vegetation;

Class 8-open soil (extra-barren areas), without vegetation (anthropogenic areas);

Class 9-cleves, scarps;

Class 10-river erosion evolution;

Class 11—estuaries in Zhaiyk river basin;

Class 12-scrubs in Zhaiyk river basin;

Class 13-areas with wet grass communities;

Class 14-sor-affected declines;

For the comparison of selected classes, we used the topographic bases of 1: 50,000, 100,000 and 200,000 scales (Figure 8).

The process of classes' selection was the following: the largest area $1,222,800 \mathrm{sq} \cdot \mathrm{m}$. is occupied by extrabarren, anthropogenically disrupted area. Sor-affected declines that are spread mainly in the eastern part of the uplift, also occupy a large area: 555,300 $\mathrm{m}^{2}$. Within the uplift territory, the area of large and medium-sized sinkholes is equal $900 \mathrm{~m}^{2}$ (total area-1800 sq.m). Small sinkholes are wide-spread there. The occupied by them area is $55,530 \mathrm{~m}^{2}$. Gypsum hills occupy $7200 \mathrm{sq} \cdot \mathrm{m}$. territory. Area of man-made quarries is $1800 \mathrm{sq} \cdot \mathrm{m}$.

\subsection{Research Object Mapping}

After the space image classification the map called "Relief of the Inder salt-dome upland" was drawn with the legend (was shortened in the article). It shows the development of certain relief forms and types on the Inder salt-dome upland (Figure 9). The legend matches the above selected 14 object classes.

Thus, the Inder salt-dome upland is a paradynamic junction, consisting of a highly karsted Inder mountains, which correspond to the large diapir uplift and large ellipsoidal, in shape, the Inder lake, with an area of $115 \mathrm{~km}^{2}$ and with the water's edge of $23 \mathrm{~m}$ below sea level. Nutrition of the lake is accomplished by snowmelt and rain water, springs and groundwater that come from the Inder Mountains. The lake stretches from north-east to southwest. Its northern and western shores are steep and bold, reach over $20 \mathrm{~m}$ in height, and are cut by short slit-like and trough-shaped ravines and gullies. At the northern shore of the lake there are springs in the gullies with mineral water, the total number of which is 80 . One of them is Aschebulak, which is located on the north-east shore of the lake, and is used for balneological purposes. Average annual output of springs is $78.2 \mathrm{l} / \mathrm{s}$, which vary over a wide range (33 - $144 \mathrm{l} / \mathrm{s}$ ) [10]. The northern coasts are composed of gypsum overlaid by quaternary

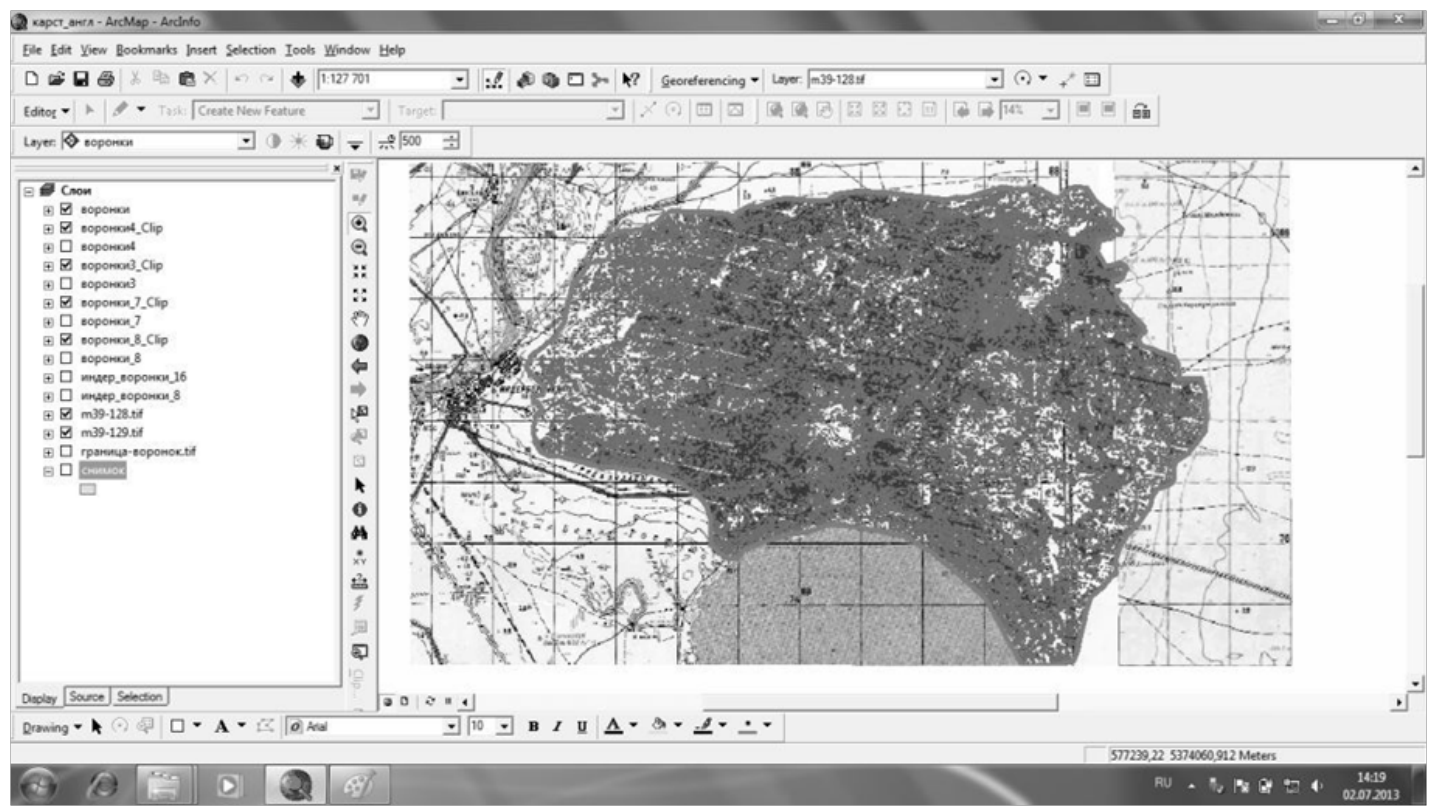

Figure 8. Mapping of the space image over the topographic base. 


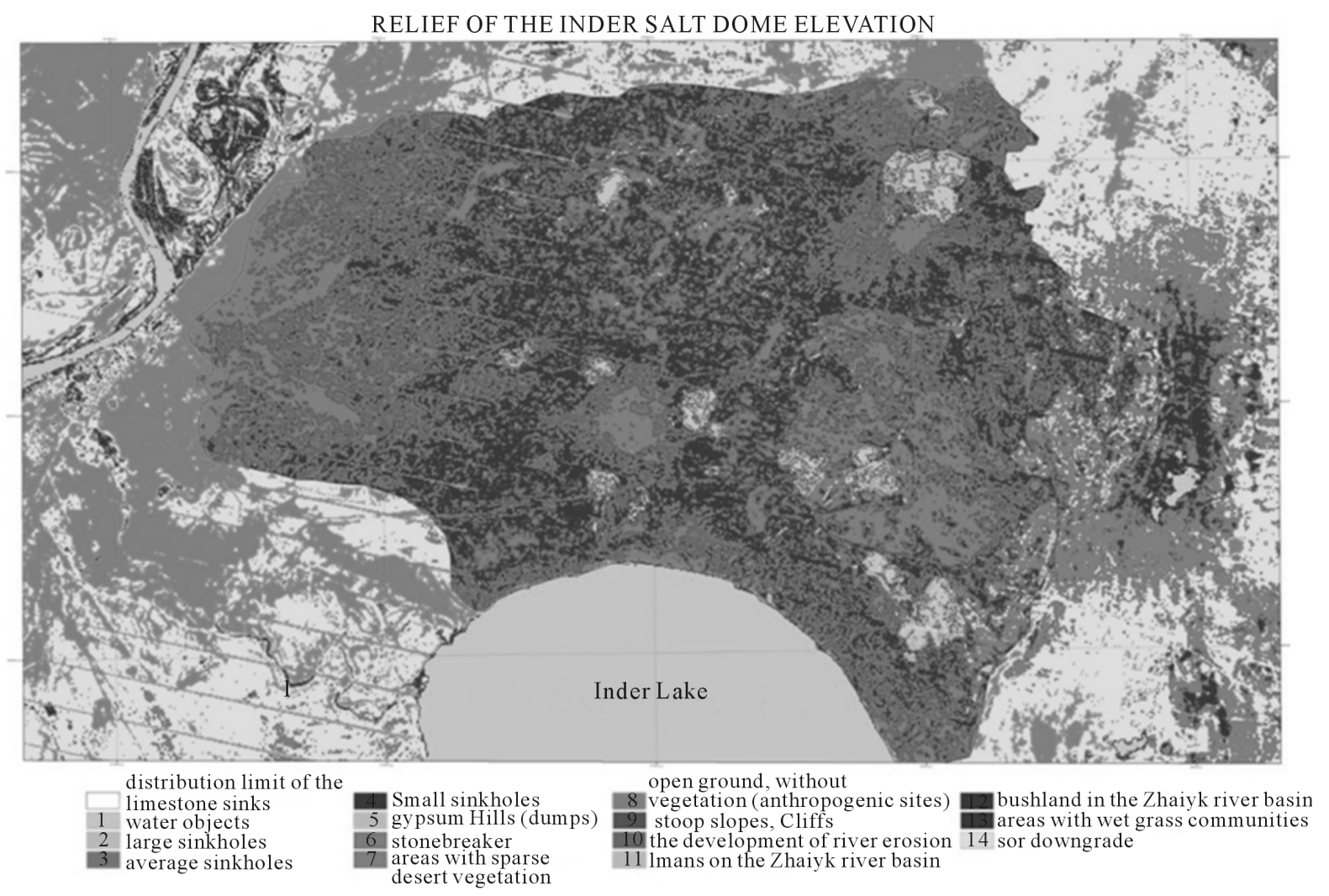

Figure 9. Karst relief of the Inder salt-dome uplift, composed according to the Landsat 5TM space image (30 m resolution, 2012).

deposits. Two springs, Belaya Rostosh and Aksai run into the lake from the north-west, which expose the Jurassic and chalk deposits. Eastern and southern shores are flat and cut by wide beams. Karst field of the Inder Mountains is the largest in the Pricaspian lowland. The total number of karstic forms reaches 5000. The density of surficial karstic forms reaches 200 - 300 pcs $/ \mathrm{km}$. The total amount of surface lowering caused by the karst processes is $1.87 \mathrm{~mm}$ /year. Four types of karst sinkholes are the most noticeable-saucer-shaped, cone-shaped, ponor-shaped and well-shaped. Saucer-shaped sinkholes are spread everywhere, but mostly all around the Inder mountains periphery. They reach 10 - $15 \mathrm{~m}$. in diameter and 2 - $3 \mathrm{~m}$ in depth. Cone-shaped sinkholes reach $20 \mathrm{~m}$. of depth and 30 - $40 \mathrm{~m}$. of diameter. Ponor-shaped sinkholes have a cone shape with a narrow chink (ponor) in its bottom, which serves as drainage channel. Karst wells are peculiar enough: being of small sizes (up to $5 \mathrm{~m}$. in diameter), their depth reaches $15 \mathrm{~m}$. Some karst kettles and sinkholes are spread on the south and south-east of the Inder lake. S. S. Korobov and I. K. Polenov [11] identify a number of factors contributing to the karst development on the Inder upland:

1) The composition of the cap rocks (gray medium-grained gypsum);

2) The cap rocks fissuring (deep open fissures of 10 - $16 \mathrm{~m}$. of depth, and even more);

3) Elevation of carsting massif above the basis of erosion (up to 35 - $40 \mathrm{~m}$. above the Inder lake);

4) Climatic conditions (continentality and climate aridity, rain showers); karst is active in the period of snow and rain showers;

5) Low power of coverings (Khvalynian) formations and their sandy (fine sandy loam and light loam) composition.

Morphological structure of the Inder salt dome landscape is complemented by a two-deck lake terrace that stretches along the southern and south-western coast of the lake. Fragmentarily, the terrace occurs along the northern and eastern shores. The lower layer of the terrace is located at a height of $1-1.5 \mathrm{~m}$. above the water's edge of the Inder lake, the upper layer 7 - $8 \mathrm{~m}$. It is obvious, that the coasts abruptness of the Inder lake, related to the compensating trough, have the tectonic causality. The surface of the Inder salt dome (directly beneath the 
north shore) is inclined at an angle of $85^{\circ}$, and within the Inder mountains $5^{\circ}-30^{\circ}$ [12].

The Inder denudation karst hill, obviously, is a relic of the ancient peneplain, which was first raised and eroded, under the influence of salt tectonics, and then underwent the karst-denudation preparing with the formation of various micro-and meso-forms of relief. Formation of the largest Inder karst field in the Caspian lowland, relates, mainly, to the secondary cap rock, which completely covers salt-glass of the dome on the area of 230 $\mathrm{km}^{2}$. The power of karst-tectonic breccia, which builds up the cap rock, is about $50-60 \mathrm{~m}$. Cap rock is built up by rock-salt, potassium salt and potassium-magnesium salts (halite, sylvite, carnallite, potassium sulfate and magnesium), anhydrite and by other rocks. The boric mineralization appeared in the assises of potassium and potassium-magnesium salts (kaliborite, boracite, hydroboracite, etc.) with the $\mathrm{B}_{2} \mathrm{O}_{3}$ content in the rocks and with the level of $1 \%-5 \%$ [13].

Formation of secondary (karst-tectogenic) cap rock is associated with the wet postglacial epochs, and with the leaching by sea water during the Caspian transgressions periods. Process duration for the formation of cap rock mass has led to the formation of various minerals, including unique ones-vitchit, hergheyit, hydroboracite, inderboryte, inyoite, colemanite, kurnakovite, sulphoborite [13].

Inder dome cap rock is watered by the fractured-karstic suprasalt waters, connected with fractured karsted gypsum, anhydrite, and sandstones. Inder cap rocks have an extremely high filtration capacity (300 - 500 1/day), [14]. Aquifer recharge is accomplished by the atmospheric precipitation and transit streams directed towards the Inder lake. 32 springs with various water discharges - from centiliters to a few tens liters per second come to the surface at the northern shore of the lake. The total discharge of all springs, at an average, is $35.25 \mathrm{l} / \mathrm{s}$ (or $1.1 \mathrm{mln}$. $\mathrm{m} /$ year). The most powerful is the Aschebulak spring (22.5 l/s).

The geomorphologic feature of the Inder denudational-karstic hills is the differences between the north-western and south-eastern parts (Figure 9). The north-western part of the hill is like a slightly rolling plain covered with many small sinkholes and kettles, but its south-eastern part is covered with ribbed ridges, which represent the slopes of large karst valleys and basins filled with terrigenous deposits [15].

Inder Mountains are characterized by the forms of inside meso-and micro-relief, belonging to various highgenetic levels. The internal structure of the Inder mountains' relief can be defined mainly by the salt table irregularities of the salt dome upland, which is complicated both by diagenetic forms of secondary salt tectonics (salt spines and stocks) and by forms of underground and surface karst formation.

In particular, the so-called "kurgan-tau", peculiar to central part of mountains [16], is the crescentic ridges with a ribbed top, built up by the compacted reddish gypsum, and the slopes of white gypsum. The feet of the ranges turn into the flat inter-ridge valleys. Presumably, the formation of "Kurgan-tau" was caused by the dissolution of salt folds on the surface of salt uplift and the collapse of the gypsum roof. The formation of tectonic faults systems over rising salt spine has played a leading role in the formation of karst ridges. This system represented the radially and concentrically divergent fissures, which have broken up a lifting hill into the separate sectors. Some of the sectors were eroded and destroyed after, what has lead to the formation of ribbed ridges like "Kurgan-tau" (Figure 9). Obviously, "Kurgan-tau" is the slope of large karstic basins, cropping out to the surface, and inter-range valleys - are the flat bottomed surfaces of the fragmentary material filling the basins.

The influence of desalination processes is typical for soils and vegetation of the Inder salt dome upland. Morphological structure of the Inder mountains landscape is formed by two components: 1 ) the sloping ridges with broad ravines with a slight or without any karst formation process, 2) highly-carsted ranges and plateaus.

Steppe formation processes occur on the karsted landforms of the Inder mountains. There are peculiar darkcolored soils with abnormally thick humus horizon $(70-80 \mathrm{~cm})$ in the karst basins and hollows. However, in general, the infantile and highly fragmented soil with short profiles, dominate on the Inder karst field under the high mosaicism and soil cover variability. Also, a meadow-steppe vegetation with shrubs (Spiraea, Rhamnus cathartica, honeysuckle, wild apple, rose, astragalus), peculiar for this landscape region, grows in karst basins. For example, Eurotian-community (Ceratoides sp.-Artemisia lerchiana) together with anabasis (Anabasis salsa), feather grass, (Stipa capillata L.), and bulbous bluegrass (Poa bulbosa L.) occupy large areas.

\section{Conclusions}

Deciphering of the Inder lake area space images shows that the use of GIS technologies (automated deciphering) gives a great opportunity to solve more complex problems in geomorphology according to the morphogenetic research method, which is acknowledged by the following results: 
1) The Inder salt-dome upland area was and still remains the largest region of the karstic rocks and salt-dome tectonics' development in Kazakhstan;

2) On the basis of space images' processing, the morphographic and morphometric parameters of the development of various karst relief types of the Inder salt-dome upland have been identified. A total karst development area has been determined by the space image. Its area is about $210 \mathrm{~km}^{2}$;

3) Combined use of «ENVI» and «ArcGIS» programs for the detailed «Landsat» space images processing by applying the large-scale topographic base has allowed to select 14 classes of objects on the studied territory, that correspond to certain morphogenetic complexes of landscapes in arid climatic conditions of Kazakhstan;

4) The map named "Relief of the Inder salt-dome upland" is the result of research. During the process of map plotting, the legend has been developed, which reflects the modern dynamics of karst relief development on the Inder salt-dome upland.

Thus, the deciphering of the Inder lake area space images confirms that the karst relief, at present, continues to develop on this territory and reflects the process and dynamics of modern relief-forming processes in conditions of salt-dome tectonics of the arid territory of Kazakhstan.

\section{Acknowledgements}

The authors express their gratitude to the Ministry of Education and Science of the Republic of Kazakhstan for the help in the implementation of this research within the frames of the 363rd project, called "Modern reliefforming processes in the oil regions of Western Kazakhstan".

\section{References}

[1] Smirnov, L.E. (2005) Aerospace Methods for Geographic Studies. Saint Petersburg, Publishing Office of Saint-Petersburg State University, 348.

[2] Knizhnikov, Y.F., Tutubalina, O.V. and Kravtsova, V.I. (2004) Aerospace Methods for Geographic Research. Publishing Centre “Akademia”, Moscow, 372.

[3] Vinogradov, B.V. (1976) Space Methods for Environmental Study. Publishing House Mysl., Moscow, 21, 285.

[4] Kravtsova, V.I. (1980) Space Survey Materials and Their Use in Geographic Research. Moscow State University Publishing Office, Moscow, 98.

[5] Labutina, I.A. (2004) Space Images Deciphering. ASPECT PRESS, Moscow, 16-19, 184.

[6] Knizhnikov, Y.F., Krenert, R., Kauttsleben, H., et al. (1982) Deciphering of Multizone Space Images. "Nauka” Publishing Office, Moscow, 7, 84.

[7] Vereshaka, T.V., Zverev, A.T., Sladkopevtsev, S.A. and Sudakova, S.S. (1990) Visual Methods Deciphering. Publishing House "Nedra”, Moscow, 4-5, 344.

[8] Golovachev, I.V. (2012) Karst Area of Lake Inder. Geology, Geography and Global Energy Journal, 45, 7-16.

[9] Tokareva, O.S. (2010) Processing and the Interpretation of the Earth Remote Sensing Data. Work Book, TPU Publishing House, Tomsk, 41-43, 66-70.

[10] Tychino, Y.I. (1953) Some Features of Thermal Regime of the Inder Lake Inter-Crystal Brine. Works of Limnology Laboratory, Moscow, 139-147.

[11] Golovachev, I.V. (2010) Karst and Caves of the Northern Caspian. Astrakhan University, Astrakhan, 215.

[12] Zhuravlev, V.S. (1968) Geomorphological Features of the Depressed Compensation Troughs of Caspian Basin: Geomorphological Analysis during Geological Studies in the Caspian Basin (Methods and Results of Study). The Editorship of L.B. Aristarkhova, Moscow, 77-86.

[13] Pekov, I.V. and Abramov, D.V. (1993) Inder Deposits of Bur and Minerals. World of Stone, 1, 8-13.

[14] Korotkevich, G.V. (1970) Salt Karst: Leningrad. Publishing House “Nedra”, Moscow, 256.

[15] Petrischev, V.P., Chibilev, A.A., Akhmedenov, K.M. and Ramazanov, S.K. (2011) Formation Characteristics of Landscapes of the Inder Salt Dome Area. Geography and Natural Resources, 2, 78-84.

[16] Jatskevich, Z.V. (1937) Materials for the Karst Study of the Inder Upland. Izvestija Vsesojuznogo Geograficheskogo Obshestva, LXIX, 937-955. 